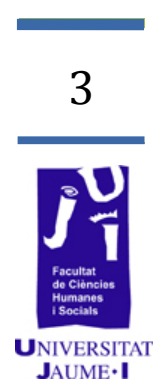

\title{
Acercamiento al concepto de publicidad política desde Kant
}

Juan Carlos Sales al189148@uji.es 
El concepto de publicidad política, entendido fundamentalmente como instrumento de crítica política, pretende establecer las garantías de justicia en las acciones e instituciones de cualquier democracia y al mismo tiempo servir de principio regulativo en el campo de lo público. En este sentido, se hará aquí patente cuál es la base filosófica del término, sus diversos modos de aplicación, su alcance y delimitaciones. Para ello se contará con lo expuesto en la obra de I. Kant en su conjunto, en la cual las raíces del concepto se aprecian de forma clara, pero con especial atención a sus escritos políticos, donde desarrolla explícitamente la idea de Publizität.

Palabras clave: publicidad política, razón práctica, medios de comunicación, Sociedad Civil.

\section{Introducción y objetivos}

El concepto de publicidad política puede ser entendido como un mecanismo de legitimación en la forma, actuación y límites de las acciones políticas y de las instituciones públicas que se quieran denominar justas. Es, por tanto, una metodología, un instrumento de tránsito entre los principios éticos (individuales), los cuales se encargarían de mostrar lo moralmente justo y su realización efectiva en las instituciones que conforman una sociedad democrática. $Y$ es, además, la exigencia de una actividad transparente y abierta por parte de las instituciones de todos los niveles (centros sociales, asociaciones cívicas, partidos políticos, parlamento, etcétera) en su empeño por mantener el horizonte moral -en este caso respecto a la legalidad- de tales instancias públicas. Estos dos aspectos básicos se encuentran intrínsecamente relacionados con la asunción de una participación activa de la sociedad civil que irrumpe como nuevo contrapoder; es decir que, a los criterios normativos de legalidad y de transparencia, se une la necesaria y potencial apertura a la participación libre y pública y, también por ello, el establecimiento de un nuevo espacio que sirva de lugar de discusión para tratar los asuntos de interés públicos o comunes.

Considerando a Immanuel Kant como el creador del concepto moderno de publicidad política y teniendo en cuenta la forma en que han influido sus escritos políticos y sociales, se partirá de su obra para analizar de forma detallada todo lo relevante respecto a tal concepto. Este, sin embargo, se deja rastrear a lo largo de todo su legado de forma implícita: desde sus escritos sobre la razón práctica y el derecho, pero también desde los que versan sobre la razón especulativa. La referencia en los escritos kantianos a la libertad (en este caso legal: de reunión, de pensamiento, etcétera), a la necesidad de una discusión pública donde 
confluyan diferentes razonamientos, a mantenerse ávidos en el pensar crítico y autónomo, es constante. La importancia que le da Kant a estos asuntos es máxima, aun cuando se ha considerado a sus escritos políticos -los que sintetizan los recursos anteriormente citados- como escritos menores; más bien al contrario, puede que este sea el objetivo más preciado de la filosofía, la pregunta última que recoja las cuestiones teórica/especulativa, práctica y teológica en el ámbito del estudio del hombre y su medio idealmente político (Gil, 2007). Autores contemporáneos hablan incluso de su filosofía como antropología o como política. ${ }^{1}$

Entrando en materia, se explicitará brevemente la importancia que el filósofo prusiano le ofrece a la legalidad y al derecho (instancias que articulan su teoría política) en tanto que piezas clave en la construcción del camino a una comunidad jurídica justa -aunque la razón nos dirija a una comunidad puramente ética inalcanzable. Este camino será marcado desde los principios morales que, a través de imperativos éticos, funcionarán como base para la posterior plasmación de las leyes en su facticidad. En este punto es donde se posiciona de modo enérgico el concepto de publicidad política en su función de ser guía del tránsito necesario entre las esferas moral y política. Pero como este término no se agota en esa sola acepción, en este trabajo se hará un repaso de las diferentes perspectivas de tan relevante y ninguneado concepto: como principio normativo, como supresión de toda opacidad hacia la sociedad, como espacio teórico y conjunto de crítica social...

\section{El uso político de la razón}

Nuestra época es, de modo especial, la de la crítica. Todo ha de someterse a ella. Pero la religión y la legislación pretenden de ordinario escapar a la misma. La primera a causa de su santidad y la segunda a causa de su majestad. Sin embargo, al hacerlo, despiertan contra sí mismas sospechas justificadas y no pueden exigir un respeto sincero, respeto que la razón sólo concede a lo que es capaz de resistir un examen público y libre.

I. Kant, Crítica de la razón pura, A XII (1781)

Immanuel Kant (1724-1804) inicia un periodo de crítica en el contexto del movimiento ilustrado del siglo XVIII que obligó a aceptar la premisa de que todo lo relevante para la razón humana debía ser expuesto a revisión por parte de un análisis crítico: desde los principios epistemológicos hasta la religión, pasando por la moral y el derecho. El

1. Posiciones de G. Vlachos y H. Saner expuestas por Adela Cortina (Muguerza, 1989: 180). 
conjunto de las tres Críticas se propuso revisar los fundamentos de los conceptos de razón pura especulativos, prácticos y teleológicos. Los temas políticos, referidos en su caso a una condición histórica o empírica, sin embargo, parecían destinados a relegarse a escritos menores 0 irrelevantes filosóficamente, temas que hablan de quaestio facti cuestiones de hecho, meramente empíricas- sin ser remitidos a ningún principio o idea de la razón a priori, esto es, sin aspirar a contar con una cierta validez en su enunciado (Marzoa, 2003: 164). Esto quiere decir que, mientras en un uso teórico-especulativo la razón pura recurre a juicios sintéticos a priori que dan cuenta de la forma universal del conocimiento $y$, de igual modo, la razón pura en su uso práctico se encarga de establecer un principio objetivo y universalmente válido a través de un factum de la razón, etcétera, la teoría política como tal no cuenta para Kant con tales fundamentos apodícticos. ${ }^{2}$

Pero ello no significa que la política no deba ser expuesta a una crítica por parte del tribunal de la razón, sino muy al contrario: quizás deba ser esta la que más sometida esté al juicio estricto, en tanto que 1) no hay un camino objetivo que le otorgue universalidad -ni puede aspirar a ello- sino que sus avances están condicionados por las contingencias históricas con que la experiencia y el tiempo le dotan, y 2) con todo, sigue siendo una pieza clave al erigirse como sustento material en donde desarrollar las demás ciencias y al conseguir llevar a la facticidad las pretensiones de la razón de un bien supremo en el mundo y la consecución de la dignidad humana general -no sólo teórica- establecida por los principios de los derechos humanos (estos sí alcanzados a priori). El peso de pensar lo político es, así, incuestionable; las personas no se conforman sólo mediante las disposiciones puras de la razón sino que son historia, y las actuaciones científicas, religiosas o éticas de cada época no pueden discurrir al margen de la acción y gestión política. La antropología, entendida como el estudio del hombre en torno a sus condiciones empíricamente dadas en un determinado contexto histórico y a las relaciones que este emprende en su socialización, se presenta en Kant como la disciplina que debe responder a una pregunta que engloba las demás actividades de la razón. Tanto el progreso científico como el moral quedan sin sentido si obviamos estudiar al sujeto empírico que las porta. Y la política, como modo de organización humana, es la que procura la situación real y de facto para que se dé tal avance. ${ }^{3}$ Habrá que profundizar, pues, en el sentido exacto que Kant le otorga a lo político y analizar tanto su sustento teórico como las partes que lo componen.

2. Es precisamente la no necesidad de tener que recurrir a la experiencia la que hace avanzar la ciencia de forma a priori con principios universalmente válidos; en cambio, para Kant, la política representa una disciplina que progresa por la propia experiencia, mediante una continua serie de intentos históricos fallidos basados en lo meramente empírico.

3. El propio Kant loa al ilustrado Federico II El Grande como rey impulsor del progreso, la libertad y la tolerancia que permite la emancipación y autonomía del hombre (y, en consecuencia, el desarrollo de todo lo demás: la ciencia, el derecho, las artes...). 


\subsection{Estructuración y objetivos de la política}

Para entender el significado que Kant le da a la política y a lo que concierne a su ámbito de actuación de manera adecuada se han de aclarar varias cuestiones previamente. Antes que nada es necesario tener presente que nos estamos moviendo en todo momento en el terreno de lo práctico, no de lo teórico-especulativo; esto es, que la razón (Vernunft) está procediendo en el campo de la actuación, no en el de la cognoscibilidad-desde la perspectiva del qué debo hacer, no desde la del qué puedo conocer. Esto significa que, en un primer momento, se establecerán las pautas del obrar moralmente correcto por principios 0 , lo que es lo mismo, entender cómo la determinación del objeto de la voluntad debe estar inmediatamente sometida a la misma ley práctica. Es este un primer paso ético que da lugar a la aparición del derecho, el cual se fundamenta en los principios morales o, por decirlo con Adela Cortina, es la prolongación doctrinal de lo ya establecido en la Crítica de la razón práctica. $^{4}$

En el derecho se desarrollarán los principios prácticos que se han obtenido a partir de esa crítica, pero esto no significa que un campo sea irreductible al otro: en el terreno ético, la actuación responde a un móvil puramente moral, subjetivo, que coacciona internamente; en cambio, en el campo del derecho, tal coacción es externa y el móvil de la acción puede determinarse sin responder a la moralidad. La acción puede ser, en última instancia, la misma, pero el móvil que se sigue para actuar definirá si esta acción ha sido configurada conforme a la moralidad (ética) o a la mera legalidad (derecho). Es sobre esta legalidad, basada en el derecho y la coacción externa, en la que surge la política para Kant. Es decir, que hemos pasado de unos principios éticos que estructuran y dan sentido moral a la legalidad para posteriormente transitar de una metafísica del derecho (que también se abstrae de todas las condiciones de la experiencia) a los conceptos de la teoría política, aplicando esos conceptos a los casos empíricos de organización social e institucional (Kant, 2010: 193).

Hasta aquí el proceso que constituye la base de la teoría política en su fundamentación moral/legal; cabrá preguntarse ahora cuál es el sentido mismo de la política en Kant. Su principal cometido es, como hemos visto, la aplicación del derecho: trasladar los principios extraídos de la teoría al terreno de lo fáctico y articular esos principios en una determinada sociedad de modo efectivo, proceso mediante el cual posibilita la constitución de una comunidad jurídica. ${ }^{5}$ En palabras de Dulce María Granja, Kant comprende la política tanto como una filosofía del derecho como del Estado que se funda «sobre los principios morales de la coexistencia humana» (2010: 228). Es esta una muy breve aclaración de la estructuración y fundamento de lo moral y lo político en Kant, pero

4. Estudio preliminar a La metafísica de las costumbres (1994).

5. Soy consciente de que hay otras muchos otros temas a tratar en este terreno: el tema de la insociable sociabilidad, su polémica del contrato social, la cuestión teleológica y el llamado "fin final», etcétera. Son estas, sin embargo, cuestiones poco relevantes para el objetivo de este trabajo. 
suficiente como para entender correctamente el concepto de publicidad política (y que, aun perteneciendo este a la política, procede tanto desde la moralidad como desde la legalidad, como veremos más adelante).

\section{De la moralidad a la política}

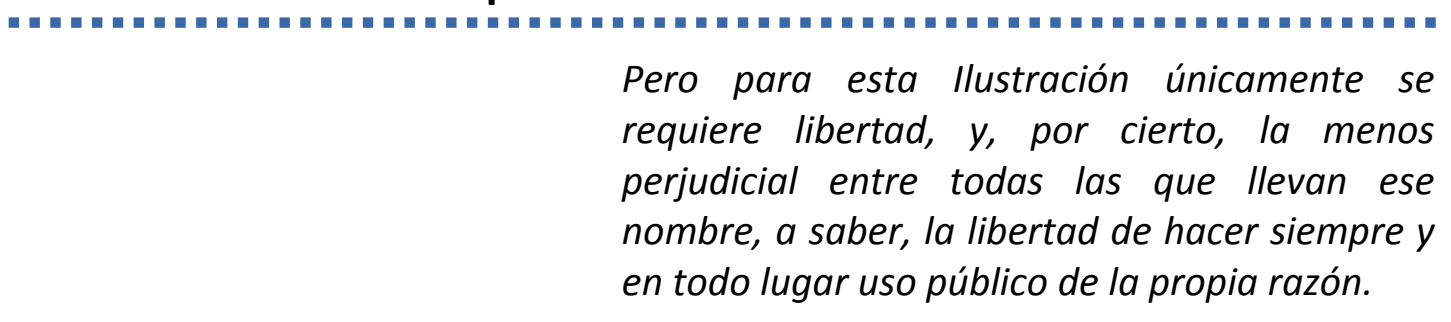

De lo dicho en el apartado anterior se siguen dos temas que se desenvolverán aquí: la importancia de la crítica y su ampliación en la política. Estos dos temas, por tanto, se van a desarrollar de manera conjunta, y se estudiará su combinación necesaria al servicio de aquello que Kant había denominado una sociedad justa (o sea, una comunidad jurídica establecida). ${ }^{6} \mathrm{Si}$ entendemos que esta sociedad y sus características sólo pueden darse en un estado de democracia, se hace comprensible a la vez la permanente necesidad de un profundo examen de los diferentes ámbitos y actores que la componen. La democracia es concebida de este modo como un sistema político y social basado en un poder limitado por el propio pueblo; democracia como modo de gobierno que se basa en la necesaria representación de los ciudadanos, en el sentido republicano moderno. Kant es tajante en este sentido al invocar una constitución republicana como la instancia que institucionaliza los principios democráticos de libertad, igualdad y sometimiento a la legislación, así como la separación de poderes (legislativo, ejecutivo y judicial); es esta constitución la que emana, además, del propio pueblo y la que dota por tanto de significación las normas jurídicas (Kant, 2010: 148-9).

Para el filósofo prusiano es importante entender la carga moral que supone el estar sometido a tal constitución, pues es la que nace del concepto de derecho, como hemos ido viendo hasta ahora. Esta dimensión moral es la que obliga subjetivamente al ciudadano a comportarse como tal y a implicarse en los asuntos de su propia sociedad. Aquí ya no se es un mero súbdito al servicio de unos intereses incuestionables, sino que los ciudadanos, organizados en sociedad civil, ${ }^{7}$

6. Obvio de nuevo una parte primordial en la consecución de un fin imperativo para el hombre como es la necesaria adaptación de la felicidad a la vida moral. Aquí no presenta relevancia para la parte de justicia política estrictamente, pero en Kant -contrariamente a lo que se suele pensar- la persecución de una vida feliz, para nosotros y para los demás, ocupa un lugar central en sus escritos (Kant, 2011: 221, 232, 244).

7. Entiendo el sentido de sociedad civil, siguiendo a Feenstra y García-Marzá, como «concepto complejo que pretende dar razón de ámbitos de interacción donde las capacidades de los sujetos para actuar y organizarse no depende directamente del Estado» (2008: 7). 
estarán dispuestos a debatir sobre todo lo relacionado con la comunidad y analizarán con inteligencia e integridad las diferentes facciones de esta. Este principio es intrínseco a la filosofía política kantiana vertida desde la óptica jurídica, y asimismo el ciudadano moral (dotado de libertad práctica) no es sólo aquel al que se le aplica una determinada legalidad sino el que es al mismo tiempo colegislador del derecho al que está sometido. Esta esencial interacción moral entre la sociedad y su Estado se muestra como categoría clave en la constitución del ciudadano del mundo kantiano y rompe a la vez con el estatismo $-\mathrm{y}$ muchas veces también paternalismo- del que hacían gala precedentes teorías políticas contractuales.

Como se aprecia, el espíritu crítico que Kant había concedido tanto al campo especulativo como al moral no se ha agotado ahí, sino que sigue siendo válido para los asuntos que afectan al modo de organizarse, esta vez constituyéndose como participación social -o lo que es lo mismo, participación ciudadana. El trabajo de crítica propio de la llustración sigue vertebrando el proyecto kantiano $y$, en relación a la política, esto comporta poner a exposición pública todo aquello que está en contacto con los asuntos de la comunidad (lo público o lo común). El criticismo continúa encarnando el espíritu del método que otorga a la razón la herramienta para validar la pretensión de justicia de una determinada actuación o institución pública, por ejemplo. Con esto llegaríamos a la conclusión de que todos los aspectos políticos, institucionales, sociales, etcétera, deberán hacerse públicos ante los ciudadanos para su libre examen mediante la razón ordinaria.

\subsection{Sentido común y discurso}

Para terminar de adentrarnos en los aspectos fundamentales de la teoría kantiana que sirven a este trabajo, cabe explicar un último apartado. Para ello es importante advertir que la razón humana es entendida en Kant como un "sentido común». Todos y cada uno de los ciudadanos, que estén en disposición de emplear todas las facultades del juicio, tienen igual capacidad de entendimiento o de uso de razón. El escrutinio de lo político puede hacerlo cada hombre sin distinción, aun aceptando las diferentes aptitudes que se sobreentienden con respecto a la naturaleza y la genética individual, porque en cada hombre se encuentra ya un sensus communis; este "sentido» es el mismo entendimiento común humano. ${ }^{8}$ Lo que se quiere evidenciar con esto es que no es útil realizar una crítica desde parámetros parciales o dirigida sólo por una élite intelectual, sino que hasta el más vulgar (vulgare) entendimiento dispone de la suficiente capacidad como para someter a crítica aquello que afecta a la sociedad, puesto que este tiene la capacidad de poder pensar por sí mismo y a la vez de estar en

8. «Pero por sensus communis ha de entenderse la idea de un sentido que es común a todos, es decir, de un Juicio que, en su reflexión, tiene en cuenta por el pensamiento (a priori) el modo de representación de los demás para atener su juicio, por decirlo así, a la razón total humana (...)» (Kant, 2007: 331). 
condiciones de ponerse en el lugar de cualquier otro ${ }^{9}$ (Kant, 2007: 332). En su artículo "Pensar por sí mismo y publicidad», Margin Ruffing concede incluso a este sentido común connatural a la humanidad un puesto decisivo: ser la condición necesaria mediante la cual puede darse la publicidad misma (2013: 75).

Además, esa "razón compartida» aparece como la posibilitación de la puesta en común de argumentos y la esperanza de encontrar soluciones conjuntas a conflictos necesariamente sociales. Sobre este supuesto se apoya el principio procedimental de la ética discursiva en su intento de hacer dialógicos los principios formales deontológicos y a este respecto comenta Karl-Otto Apel (Cortina y García-Marzá, 2003: 28):

Todos los seres capaces de comunicación lingüística deben ser reconocidos como personas, puesto que en todas sus acciones y expresiones son interlocutores virtuales, y la justificación ilimitada del pensamiento no puede renunciar a ningún interlocutor y a ninguna de sus aportaciones virtuales a la discusión.

Sin entrar ahora a explicar detalladamente los aspectos de la ética discursiva, conviene resaltar que esta filosofía pretende desentrañar la validez moral del discurso través de las estructuras comunicativas. Aquí interesa remarcar la idea central del interlocutor válido, o persona reconocida como participante en el proceso comunicativo precisamente por compartir el sentido racional común, por el cual sería reconocido como válido. ${ }^{10}$ Es decir, que sólo pueden ser válidas aquellas normas sobre las cuales podrían estar de acuerdo los participantes del discurso de forma a priori. Durante todo el proceso se pone de relieve la igualdad de los participantes y su reconocimiento recíproco (reconocer al "otro», ponernos en su lugar), lo que posibilita la relación intersubjetiva necesaria para pretender la validez moral del discurso (García-Marzá, 1992: 43).

\subsection{El concepto de publicidad política}

El concepto de Publizität ${ }^{11}$ aparece esparcido por varias obras del corpus kantiano, aunque es explicado de modo preciso en su escrito Hacia la paz perpetua (Zum ewigen Frieden), concretamente en sus apéndices finales. Pero teniendo en cuenta todo lo que ha sido expuesto aquí hasta ahora, se puede decir que la procedencia del término, lo que constituye la idea que después se desarrollará, está presente de modo explícito en casi todos sus escritos anteriores. No hay que olvidar que

9. Un «otro» no en sentido empírico, haciendo referencia a una persona o una comunidad concreta, sino en el sentido trascendental de un interlocutor ideal.

10. Aunque se debe advertir que en tales procesos de la ética del discurso sólo participan aquellos interlocutores que -además de contar con la razón común- son a la vez afectados por una situación normativa concreta, y esto último es también condición precisa de su validez como tales (Cortina, 2003: 29).

11. La terminología alemana distingue entre Publizität/Werbung lo que en español se traduce por la palabra 'publicida'. La primera de ellas, sobre la que versa este trabajo, es el concepto filosófico-político que se desarrolla en el apartado actual; la segunda posee un significado relativo simplemente a la actividad comercial. 
Hacia la paz perpetua es uno de los últimos trabajos de Kant, publicado en 1795; pues bien, podría decirse que al menos desde el comienzo del periodo crítico, iniciado en 1781 con la publicación de la Crítica de la razón pura, hay ya toda una serie de conceptos que subyacen a la idea de una razón pública y libre que camina de la mano del criticismo. Para evidenciar esto hay que recurrir a las obras escritas en este periodo; se observa en los prólogos o notas que, fuera de la temática concreta del opúsculo -epistemológica, moral, etcétera-, el conjunto general responde al interés de crear una sociedad o comunidad mejor y más justa como el fin de nuestra misma naturaleza (Kant, 2010: 25, 39). Y la consecución de una comunidad justa mediante la política comporta, a su vez, el medio por el cual el hombre puede alcanzar su realización en tanto que sujeto moral.

Con el objetivo de esclarecer un poco más el camino que da sentido a la aparición de la publicidad política, creo necesario puntualizar que, según Kant:

1. No hay ningún conflicto entre la moral -base de la teoría del derecho- y la política -aplicación de dicha teoría. No hay un conflicto como tal, pues, entre teoría y práctica. De hecho sería una contradicción (Widerspruch) asumir que las leyes morales, que son regulación de la praxis en su esencialidad, no pueden realizarse en el mundo real; pues en este caso perderían todo el sentido.

2. Cuando se produce algún conflicto en la aplicación de la teoría en la práctica, se ha incurrido en una desviación de la idea teorética en la experiencia real; de este modo ha fallado la aplicación de ésta (puesto que una ley moral teórica resulta clara e inequívoca para la razón común) por parte de quienes detentan el poder y se encargan de dar ese determinado paso. Dos ejemplos clarificadores de esto que el propio Kant da son: 1) el jurista como tal se encarga de aplicar las leyes que se dan sin investigar si necesitan mejora (pudiendo haber algún principio no moral en ellas); y 2) el gobernante que por su parte las toma y puede hacer de ellas un uso egoísta con vistas a su propio beneficio.

3. La solución a este problema común radica en la capacidad crítica e imparcial de los filósofos (entendidos como teóricos de la moralidad y el derecho). Los filósofos no deben, con todo, convertirse ellos mismos en políticos, ${ }^{12}$ pues es el mismo poder el que «daña inevitablemente el juicio de la razón» (Kant, 2010: 169). Así, la premisa fundamental para mantener saludable el estado de una democracia justa es, en

12. Es, de nuevo, el método trascendental kantiano el que aquí se refleja en tanto que no se toma parte en, ni desde, un bando o perspectiva de la «disputa», sino que llama a mantenerse en un tribunal independiente de la contienda a la que se juzga -desde fuera-, única vía por la cual se consigue la imparcialidad necesaria como para progresar del modo más objetivo (Kant, 2012: 9-10). 
primer lugar, permitir a los teóricos expresar sus denuncias y críticas públicamente.

Resumiendo esta última parte, no hay conflicto como tal entre moral y política de modo objetivo, pero sí subjetivamente (debido al egoísmo por parte de quien ostenta cualquier tipo de poder). En palabras de Kant (2010: 180):

la verdadera política no puede dar un paso sin haber antes rendido pleitesía a la moral, y, aunque la política es por sí misma un arte difícil, no lo es, en absoluto, la unión de la política con la moral, pues esta corta el nudo que la política no puede solucionar cuando surgen discrepancias entre ambas.

Alguna de las "soluciones» a tal problema moral, hasta que los gobernantes utilicen su poder de forma estrictamente acorde a la justicia, será la continua vigilancia de los asuntos públicos y ahí entra finalmente en acción la publicidad política.

Una última precisión al respecto: en Kant no se encuentra, como se deduce de lo dicho hasta ahora, una distinción entre la ética y la política en un sentido maquiavélico por el cual la política no debe responder necesariamente a la moral, argumentando que son ámbitos de acción diferentes, de manera que es aconsejable incluso que el gobernante sepa controlar al pueblo con técnicas como la mentira, el secretismo, etcétera, pues son estos instrumentos los que proveen de éxito a todo gobierno (Luban, 1988: 155). En Kant la política es el continuo intento de realización de las mismas ideas morales y que sea el gobernante el que se desvíe de los cauces normativos por intentar aproximarse cada vez más al ideal moral -engañando, mintiendo, al fin y al cabo no respondiendo a la objetividad ética- es un puro sinsentido teórico. Por tanto la política no se deja de suyo reducir al campo instrumentalizante de la razón (el cómo actuar según la mera prudencia, prevaleciendo la consecución de un fin cualquiera sobre los medios) sino que debe responder siempre a la razón práctica y al campo normativo basado en los principios morales.

\subsection{Las formulaciones del término}

Para esta parte del trabajo se van a analizar los aspectos precisos de la publicidad política desde el trabajo de García-Marzá (2012). En su artículo "Kant's Principle of Publicity» se presentan hasta tres formulaciones distintas de este concepto atendiendo a su determinada aplicación; representa por ello un concepto amplio y polifacético que precisa de una delimitación de sus partes. Antes de continuar, debe indicarse que estamos manejando un concepto que constituye ni más ni menos que la forma del derecho público, ${ }^{13}$ y que responde por ello a la pretensión de legitimidad de lo que se quiere denominar justo al ser él

13. La noción de forma es entendida aquí como la constitución o esencia misma de la justicia, la que le otorga validez a priori -sin materia; es el «aquello en lo cual consiste» y, por tanto, la propia condición de posibilidad del derecho (Marzoa, 1989: 24-25). 
mismo el garante de la pretensión jurídica (Kant, 2010: 181). Pues bien, en el segundo apéndice de Hacia la paz perpetua se encuentran un par de citas que Kant desvela como las fórmulas explícitas de la publicidad política, a saber: "son injustas todas las acciones que se refieren al derecho de otros hombres cuyos principios no soportan ser publicados" y «todas las máximas que necesitan la publicidad (para no fracasar en sus propósitos) concuerdan con el derecho y la política a la vez» (Kant, 2010: 181-186).

La primera formulación del término es acaso la más conocida o la que se suele estudiar de forma más recurrente. Se trata de un principio que enfrenta las acciones políticas al examen de la publicidad para verificar su posible condición de injusticia. Cabe advertir que cuando hablamos de examinar la justicia de las acciones políticas no se está evaluando a la acción empírica misma, sino -de nuevo- a su forma, que en este caso representa la máxima subjetiva que subyace a toda acción posible. ${ }^{14}$ Además, se requiere aquí que la máxima de tal acción sea justa, pero, como se explicó en un apartado anterior, no por mor de la ley práctica (lo que atañe a la moral) sino simplemente conforme a ella. Teniendo en cuenta esto, se puede decir que esta formulación del principio de publicidad es una idea de la razón, hipotética y enteramente formal, que abstrae todo lo empírico de la acción con el fin de comprobar su validez jurídica. Es, en definitiva, un imperativo categórico, pues procede con universal validez y necesidad, pero no pertenece al campo de lo ético sino que cae dentro del ámbito de la política y por ello no se refiere tanto a la libertad personal o individual como a la libertad y actuación de la comunidad (García-Marzá, 2012: 109). Como se aprecia, es esta una formulación a modo de herramienta en la que se juzga la posibilidad de que una máxima sea injusta, pero no de que esa misma máxima pueda ser, de hecho, justa; es un principio puramente negativo en este sentido, que no nos sirve para determinar lo que es justo sino para descartar lo injusto.

En la segunda fórmula de la publicidad - «todas las máximas que necesitan la publicidad (para no fracasar en sus propósitos) concuerdan con el derecho y la política a la vez»- podemos rastrear en cambio un sentido positivo del concepto, recordando lo que se dijo de que todo ciudadano es, por el hecho de serlo, al mismo tiempo colegislador del Estado de derecho. Esto significa que se requiere del consentimiento por parte del ciudadano del sistema de leyes y políticas que se establece sobre la sociedad. Se trata ahora de un escrutinio continuo de las acciones e instituciones del ámbito público que nos afectan, las cuales deben ajustarse a la idea -compartida- de derecho aras de conseguir nuestra aceptación como miembros colegisladores. Por ello esta formulación, además de transparencia, busca principalmente el acuerdo

14. Se trata de la misma distinción establecida para la moral en la Fundamentación para una metafísica de las costumbres, donde se sostiene que "una acción por deber tiene su valor moral, no en el propósito que debe ser alcanzado gracias a ella, sino en la máxima que decidió tal acción» (Kant, 2008: 74). 
mediante la participación abierta de los ciudadanos en torno a la justicia y su institucionalización.

A este respecto se debe leer con Luban (1988: 156) que el concepto de publicidad «no es sólo una proposición de la moralidad, sino que además es también un principio de diseño institucional». Una acepción positiva, como vemos, y que apela al consenso de los ciudadanos pero que no ha sido explotada en sus consecuencias como sí lo ha sido la formulación negativa. Cabe resaltar que lo que aquí se pone en juego no es un dispositivo que sirva para describir de modo histórico lo que han sido y son las instituciones existentes -asunto que también deberá ser objeto de análisis- sino que por este medio se trata de cuestionar su validez, verificar los términos de justicia que son condición de aparición de tales instituciones. No es por tanto una teoría de las instituciones empíricas sino más bien una teoría de la institucionalización (GarcíaMarzá, 2012: 97).

Hasta aquí dos formulaciones de este concepto, dos formas de ver un mismo principio moral. Algunas características intrínsecas a la publicidad política, como la crítica, la transparencia o la necesidad de consensos, nos conducen a dos apartados que surgen como correlatos destinados a finalizar o encauzar tales presupuestos teóricos: uno es la comunicación de la que me encargaré en la siguiente sección-y otro es la confianza. En la praxis cotidiana actuamos de facto asumiendo unos comportamientos o actuaciones que se dan en la vida real. De hecho, actuamos como si las premisas más básicas de la convivencia se fueran a dar inequívocamente; en este "como si» se erige el concepto de confianza (García-Marzá, 2011: 105). Por otro lado, cuando se habla de permitirnos entrar en un intercambio franco de opiniones con la intención de configurarnos una posición ante un determinado conflicto y nos vemos autorizados a creer en el éxito del futuro proyecto debido a su solvencia moral, estamos depositando una confianza en el "otro» con el fin de resolver un acuerdo; y si los ciudadanos respaldan la existencia de una institución justa, si se le da el "visto bueno» moral, se está automáticamente dando credibilidad a ese proyecto y por tanto se puede confiar en él.

La publicidad juega también, así, el papel de eliminar la desconfianza (Mißtrauen) de aquellas situaciones en las que se busca un compromiso sincero y transparente, tanto dentro de la misma sociedad civil como con respecto a los organismos institucionales. Esta es una perspectiva que aúna la primera formulación de la publicidad política, en calidad de aseguradora de unos mínimos éticos, y la segunda, como necesidad de entendimiento mutuo y razonamiento compartido. Esta tercera formulación del término surge, pues, de las dos anteriores, y es la que avala el compromiso social y por el cual se puede llegar confiar realmente en lo público. En palabras de García-Marzá (2012: 113): "[w]ith this formulation Kant stresses that publicity is a condition of posibility for 
producing the necessary trust to support the credibility or legitimacy of all social order». ${ }^{15}$

\subsection{Publicidad y razón comunicativa}

Un aspecto que ha aparecido a colación de lo que se ha explicado hasta ahora y que me parece de una importancia capital es el papel de la comunicación. Es así porque cuando hablamos de los ítems de la publicidad política, como la transparencia, una fuerte opinión pública y, especialmente, el intercambio libre de argumentos acerca de un tema social cualquiera -como el hipotético ideal de justicia que deben cumplir las instituciones- estamos al mismo tiempo ocupándonos de proveer vías de comunicación entre sujetos (sociedad civil), y entre estos y los organismos públicos que componen el Estado. La comunicación es, en todos sus aspectos, una pieza clave de la publicidad política, en unos casos porque los ciudadanos son conocedores de la acciones de la esfera pública, debidamente sometidos a crítica, a través de diferentes medios de difusión; en otros casos, la publicidad promueve la instauración de un espacio público dedicado al debate y por ello mismo la comunicación se convierte en su base indispensable. Hay, pues, una conexión intrínseca entre publicidad y comunicación, que atiende a la relación natural de la política definida como un ámbito más de la esfera pública cuyos asuntos deben ser de hecho anunciados a quienes la constituyen $y$ posteriormente debatidos. Se observa a este respecto la importancia de la comunicabilidad, sin la cual no podrían entenderse términos como «publicidad» o «lo público» (Ruffing, 2013: 79).

En la filosofía kantiana queda claro que existe la idea de la razón como comunicación -o razón pública- porque, si se sigue el hilo que nos ha traído hasta este punto, el proceso dialéctico en la comunidad jurídica aparece como guía para un incesante mejor futuro del hombre y la sociedad. Toda operación política que se pretenda justa sólo puede verse refrendada cuando es dotada de validez por la razón comunicativa, esto es, por el conjunto del pueblo abastecido con su sensus communis, habiendo debido ser antes forzosamente publicitada. La aceptación o el rechazo de determinadas políticas e instituciones atendiendo a su justicia se llevará a cabo tras la puesta en común de opiniones abiertamente expuestas, a través de la acción comunicativa intersubjetiva. Habiendo explicado esto, quedaría por señalar qué condiciones hacen válido el espacio de discusión, o dicho de otro modo, qué presupuestos posibilitarían la estancia dialéctica del debate riguroso y válido.

15. "Con esta formulación, Kant recalca que la publicidad es una condición de posibilidad para producir la confianza necesaria a fin de sostener la credibilidad o legitimidad de todo orden social». 
El objetivo de este trabajo ha sido analizar el concepto de publicidad política, rastrear sus orígenes y entender su aplicación. De forma general, se han tenido presente a lo largo de toda esta exposición las definiciones intrínsecas al término, aquello que constituye su esencia. En primer lugar, se ha planteado la publicidad política como una herramienta que, a modo de transición entre los principios éticos y los estatutos del derecho, puede legitimar las acciones y decisiones de las instituciones públicas o sociales. De este modo contribuye como elemento básico de cualquier teoría de la institucionalización y ayuda a reconocer la validez moral de las organizaciones.

Por otro lado, la publicidad se ha presentado como una «manera de actuar», un principio regulativo por cuanto exige una actitud de transparencia no sólo desde instancias políticas, sino también desde las diferentes organizaciones -públicas o privadas- y hasta en los procesos de diálogo en los que se persiguen unos resultados racional y moralmente consensuados. Finalmente, la publicidad encuentra sentido también como apertura hacia el debate y la promoción, acompañada del derecho a la información veraz, de la actividad crítica especialmente en la sociedad civil e instituciones públicas.

Así pues, la publicidad política viene a significar, de modo general, tanto metodología política y moral como exigencia de transparencia e información y posibilitación de participación pública. Para el acercamiento histórico y etimológico del concepto de publicidad política me he servido de su creador moderno, Immanuel Kant. Además, gracias a la atemporal relevancia que poseen sus escritos políticos, los he utilizado convenientemente como base teórica misma sobre la que emerge el resto del trabajo. Desde aquí he mostrado cómo Kant da cuenta del principio de publicidad, desde qué espacios lo extrae (razón práctica) y cómo es un elemento indispensable de la filosofía del derecho para el correcto funcionamiento de la política. Y se ha hecho patente cómo, a partir de este punto, se han venido desarrollando todas las demás partes de este trabajo: sentido común o general, ideal ilustrado, razón comunicativa o exigencia moral son conceptos que han copado lo escrito aquí y que se han explicado detalladamente.

Creo que el concepto de publicidad política y su aplicación en la vida social contemporánea responden a una actitud de tender a mejorar la sociedad como comunidad jurídica, a recobrar la fe en el sistema político y social, a restablecer la superioridad de la democracia frente a los poderes fácticos. Este trabajo es asimismo un llamamiento hacia ese progreso. De este modo, se tendrá al menos la esperanza de poder revertir la actual situación de desafección hacia lo político. Lo que la sociedad se juega con todo ello es demasiado importante como para dejarlo en manos de la indiferencia; demasiado valioso "como para que no tenga que ser recordado de nuevo al pueblo en ocasión propicia o en los momentos de crisis» (Kant, 2010: 31). 


\section{Bibliografía}

ARREOLA, E. (2012): "La política y los mass media en la globalización», Investigación Universitaria Multidisciplinar, no 11, Universidad Nacional Autónoma de México.

BeRnAL, D. (2010): La publicidad política y el espacio público: una revisión del problema a partir de Rawls y Habermas (Tesis Doctoral), FLACSO, México DF.

Cortina, A. y D. GarcíA-MarzÁ (Ed.) (2003): Razón pública y éticas aplicadas, Tecnos, Madrid.

DAvIS, K. (1991): "Kantian "Publicity" and Political Justice», History of Philosophy Quarterly, no 8, University of Illinois Press.

Feenstra, R. (2010): Sociedad Civil: Democracia monitorizada y medios de comunicación en John Keane (Tesis Doctoral), Universitat Jaume I, Castelló de la Plana.

Feenstra, R. y D. García-Marzá (2008): "Sociedad civil: Una perspectiva crítica», Recerca, no 8, Universitat Jaume I, Castelló de la Plana.

García-MARzÁ, D. (1992): Ética de la justicia, Tecnos, Madrid.

- (2011): Ética empresarial. Del diálogo a la confianza, Trotta, Madrid.

- (2012): «Kant's Principle of Publicity», Kant Studien, no 103, De Gruyter, Berlin/Boston.

GIL, J. (2007): Aproximación antropológica a la filosofía de la historia en Kant, Forum de Recerca, Castelló de la Plana.

GonZÁlEZ, E. (1996): «Imagen social de la empresa: Responsabilidad social y toma de decisiones empresariales», Papeles de ética, economía y dirección, no 4, EBEN, España.

Granja, D. (2009): Cosmopolitismo, Anthropos, Barcelona.

- (2010): Lecciones de Kant para hoy, Anthropos, Barcelona.

GutiÉRREZ-RuBí, A. (2011): La política vigilada, UOC, Barcelona.

HABeRMAS, J. (2000): Aclaraciones a la ética del discurso, Trotta, Madrid.

KANT, I. (1977): Zum ewigen Frieden, Suhrkamp, Frankfurt am Main.

- (2005): Metafísica de las costumbres, Tecnos, Madrid.

- (2007): Crítica del juicio, Porrúa, México.

- (2008): Fundamentación para una metafísica de las costumbres, Alianza, Madrid.

- (2010): Ensayos sobre la paz, el progreso y el ideal cosmopolita, Cátedra, Madrid. 
- (2011): Crítica de la razón práctica, Alianza, Madrid.

- (2012): Crítica de la razón pura, Taurus, Madrid.

KLEIST, E. (2005): "The Principle of Publicity as Kant's Response to the Intrinsic Indeterminacy of the Highest Good», Cuadernos de Anuario Filosófico, no 173, Universidad de Navarra.

LUBAN, D. (1988): «The Publicity Principle», The Theory of Institutional Design, Cambridge University Press, Cambridge.

MARzOA, F. (1989): Releer a Kant, Istmo, Madrid.

- (2003): Historia de la Filosofía II, Istmo, Madrid.

Muguerza, R. (1989): Kant después de Kant, Tecnos, Madrid.

RAWLS, J. (2006): Teoría de la justicia, FCE, México.

RuffiNG, M. (2013): "Pensar por sí mismo y Publicidad», Ideas y Valores, no 62, Universidad Nacional de Colombia, Colombia.

SplichaL, S. (2002): "The Principle of Publicity, Public Use of Reason and Social Control», Media, Culture \& Society, no 24, Londres.

ThомAß, B. (2011): Wikileaks and the Question of Responsibility Within a Global Democracy, Centre for European Studies, Bruselas. 